Revista Destaques Acadêmicos, Lajeado, v. 12, n. 4, 2020. ISSN 2176-3070

DOI: http://dx.doi.org/10.22410/issn.2176-3070.v12i4a2020.2405

http://www.univates.br/revistas

\title{
APRENDIZAGEM BASEADA EM PROJETOS COMO METODOLOGIA DE ENSINO NO CURSO TÉCNICO EM EDIFICAÇÕES
}

\author{
Francine Maria Sauter Gutjahr ${ }^{1}$, Maria Claudete Schorr ${ }^{2}$
}

\begin{abstract}
Resumo: Perante aos inúmeros desafios encontrados pelos professores no ensino profissionalizante, para manter o interesse do aluno pelo curso, novas técnicas e metodologias de ensino e aprendizagem estão sendo utilizadas nas salas de aula. E é por meio de metodologias que instigam o aluno à pesquisa, desenvolvem o trabalho em grupo e a autonomia que, é possível ter profissionais preocupados com sua função no meio em que vivem. Tais metodologias tem impacto em seu trabalho, modo de agir e reflexão perante as pessoas que dependem de seus serviços. Neste artigo, após a contextualização teórica, é apresentada e discutida a proposta de aplicação da metodologia ativa de Aprendizagem Baseada em Projetos (ABP), na disciplina de Patologia das Edificações do curso Técnico em Edificações. Como resultado da proposta desta aplicação é esperado que o uso dessa metodologia resulte em profissionais capacitados, com conhecimento a respeito de patologias, como evitá-las e como solucioná-las, que estejam familiarizados com o que encontrarão na vida profissional, contribuindo para a formação de profissionais com o perfil que o mercado de trabalho tem buscado.
\end{abstract}

Palavras-chave: Educação Profissional; Metodologias Ativas; Aprendizagem Baseada em Projetos.

\section{INTRODUÇÃO}

Um grande desafio encontrado pelos professores de cursos técnicos de nível médio, onde os alunos são jovens/adultos, é ministrar o conteúdo de forma interessante e instigante, fazendo com que os alunos gostem da aula e aprendam de forma prática e com autonomia, além de buscarem soluções para os problemas que se apresentam, quando do exercício da profissão.

1 Graduada em Arquitetura e Urbanismo. Acadêmica do Curso de Pós-Graduação Lato Sensu Especialização em Docência na Educação Profissional da Univates.

2 Docente da Universidade do Vale do Taquari - Univates. Doutora em Informática na Educação. 
Conforme afirmam Oliveira e Araújo (2015) o desenvolvimento do estudante perante a possibilidade de aprender sempre e de transitar neste novo mundo com desenvoltura, está diretamente ligado a construção do conhecimento por meio de competências e habilidades mentais, que são treinadas durante a formação deste conhecimento. Não basta mais o simples ensino de conteúdo de forma tradicional, é preciso transformar a forma com que os alunos aprendem.

Com as mudanças da sociedade contemporânea, o mercado de trabalho tem buscado profissionais com conhecimento teórico, que se destaquem e que busquem soluções rápidas e eficientes. A fim de formar profissionais com perfil criativo, inovador e autônomo, as instituições precisam fazer com que seu currículo leve em conta esse perfil. Assim, a aprendizagem baseada apenas na transmissão de conteúdo não tem mais os resultados esperados, é preciso dar lugar a novas práticas de ensino (DIESEL; MARCHESAN; MARTINS, 2016).

Neste contexto, conforme Cit e Lima Filho (2014) na relação entre teoria e prática não deve haver discernimento, nem separação entre elas, e ainda que para compreensão entre teoria e vivência profissional devam ser utilizadas estratégias pedagógicas que facilitem esta integração. Tendo em vista a importância da relação entre teoria e prática para a formação do aluno, com a proposta apresentada neste artigo. É possível aproveitar que sejam realizadas situações e atividades com benefício também para a sociedade. Fazendo com que os estudantes tenham contato com a prática através de problemas existentes na comunidade onde vivem. Assim, o estudante ajuda a comunidade e a comunidade ajuda o estudante, transformando uma atividade de um curso técnico em uma via de mão dupla, entre conhecimento e prática.

Sendo assim, neste artigo sugere-se a utilização de metodologias ativas que auxiliem o aluno na identificação e resolução prática de problemas existentes. O principal objetivo é aproximar o aluno da realidade que ele encontrará quando tiver concluído o curso, e também dar-lhe a oportunidade de verificar problemas e discuti-los em grupo. Auxiliando na sua futura desenvoltura com colegas de trabalho, por meio do trabalho em grupo. E ainda mostrar aos alunos na prática, problemas que podem ser evitados, e instigálos a descobrir como resolver tais problemas e situações. Formando assim, profissionais que já tenham tido contato com situações práticas existentes no mercado de trabalho e, que já tenham de certa forma auxiliado em situações reais, que tenham contribuído com a comunidade e no meio em que vivem.

\section{METODOLOGIAS ATIVAS}

Na sociedade contemporânea, é importante que os professores façam uso de metodologias, que apliquem o conteúdo e desenvolvam o aluno para o mercado de trabalho. Tal pensamento deve fazer com que, os professores reflitam sobre esse processo e pensem em modos inovadores de ensino, com 
o objetivo de formar "profissionais com perfis para além da área técnica, mas também criativos, empreendedores, proativos, competentes, cidadãos responsáveis, críticos e atentos ao contexto social" (DIESEL; MARCHESAN; MARTINS, 2016, p. 154-155).

Uma forma de facilitar a aprendizagem dos alunos é por meio de metodologias ativas. Conforme Berbel (2011, p. 28), "as metodologias ativas têm o potencial de despertar a curiosidade, à medida que os alunos se inserem na teorização e trazem elementos novos, ainda não considerados nas aulas ou na própria perspectiva do professor. " É importante que o professor tenha uma boa metodologia de ensino e aprendizagem, para que o conteúdo seja compreendido em sua totalidade. Segundo Uni apud Aguilar e Gonçalves (2015, p. 2), "Nesse modelo educacional o aluno é o centro do processo, é proposto que ele desenvolva atividades e reflita criticamente sobre elas"

As diferentes metodologias ativas que podem ser aplicadas, mostram que, "aprender por meio da problematização e/ou da resolução de problemas de sua área, portanto, é uma das possibilidades de envolvimento ativo dos alunos em seu próprio processo de formação" (BERBEL, 2011, p. 29).

De acordo ainda com Boas apud Larios e Paseto (2016, p. 2), "um bom professor é aquele que não só apresenta uma boa formação, e sim, aquele que relaciona a teoria com a prática".

Assim como nas escolas de ensino fundamental e médio são aplicados métodos diferentes de ensino e aprendizagem, na educação profissional não há de ser diferente. É importante que o docente tenha conhecimento e que saiba ensinar de forma diferenciada.

O aluno que está na educação profissional, já está mais maduro, está em busca de seu futuro profissional e isto já o torna diferente de alunos de ensino básico. Como já dito anteriormente, estes alunos são jovens/adultos, que estão em busca de qualificação profissional. Como citam (RECHLINSKI; SCHWERTNER, 2017, p. 2) “O adulto com sua maturidade desenvolve a autonomia e o comprometimento com seu aprendizado, faz experiências para utilizar na vida prática, o conhecimento". Dessa forma, o aluno da educação profissional se torna coautor de seu aprendizado.

O desafio para o professor neste caso é fazer com que o aluno não perca o interesse, que sinta-se motivado perante a sua trajetória no curso, aproximando-o da vida profissional ainda enquanto estudante. Como cita Berbel (2011, p. 29), o professor pode contribuir na promoção de autonomia do estudante e ainda, na condição essencial, em ampliar suas possibilidades de exercitar ainda na teoria a liberdade e a autonomia, como forma de preparo para o exercício profissional. Onde há "o engajamento do aluno em relação a novas aprendizagens, pela compreensão, pela escolha e pelo interesse".

As metodologias ativas surgem como ferramenta para auxiliar nesse processo, pode-se citar algumas destas, como o estudo de caso conforme Berbel 
(2011), bastante usado na medicina e no direito, onde estuda-se sobre algum caso real ou fictício, baseando-se em informações que os alunos já conhecem para que obtenham suas próprias conclusões e resultados.

Outra metodologia ativa é a Aprendizagem Baseada em Problemas, onde Debastiani (2016, p. 43) cita "em que os alunos partem de um conhecimento prévio do conteúdo e em grupos discutem a aplicação deste conteúdo para resolver um determinado problema".

E a metodologia abordada neste artigo se trata da Aprendizagem Baseada em Projetos (ABP) ou ainda Project Based Learning (PjBL), que vem a ser, uma metodologia onde as atividades devem chegar a um produto e este produto, "pode ser um artefato: protótipo de alguma coisa; um vídeo; um relatório; uma apresentação ou um banner" (OLIVEIRA; ARAUJO, 2015, p. 9).

A metodologia de aprendizagem baseada em projetos, pode ser confundida com a aprendizagem baseada em problemas, por terem características em comum. Porém, a diferença entre essas metodologias é clara, quando se entende do que se trata cada uma, e principalmente qual será o resultado final delas, quando a primeira resulta em um produto final e, a outra tem como objetivo a resolução, ou o exercício final, de um problema.

Conforme Lorenzoni (2016), a ABP é uma metodologia que aposta na formação de conhecimento por meio de trabalho de investigação, que leva a resolução de um problema ou questão maior, após a execução de algumas etapas, chega-se a uma solução ou produto final. Conforme ilustrado na Figura 1 , os aspectos essenciais necessários à metodologia ativa de Aprendizagem Baseada em Projetos. 
Figura 1: Infograma de aspectos essenciais da ABP.

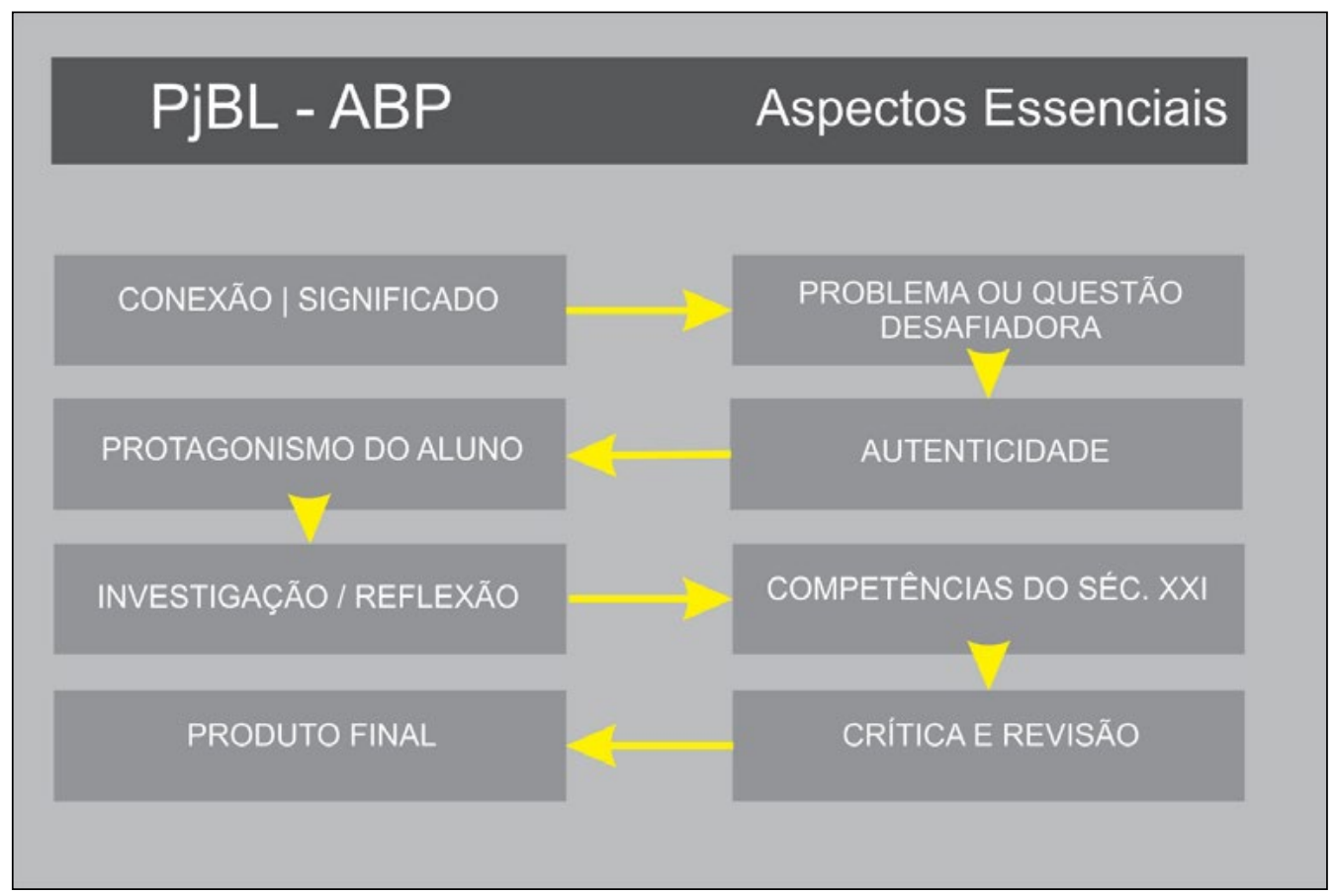

Fonte: Adaptado de Lorenzoni (2016).

Quase todos os projetos da ABP, são focados em questões ou problemas autênticos da vida real. Praticamente todas as experiências desta metodologia, possuem tarefas que os estudantes são solicitados a realizar, com características do mundo real (BENDER, 2014). Além disso, a ABP exige na sua maioria de tarefas, um amplo trabalho cooperativo, onde os estudantes precisam planejar, organizar e pensar em grupo, em equipe, para gerar avanço na solução do problema e desenvolvimento de seus produtos (BENDER, 2014).

Como cita Bender (2014, p. 18) "os projetos em ABP podem ser focados em apenas um sujeito ou podem ser interdisciplinares". É comum que trabalhe a interdisciplinaridade, pois envolve competências de diversas disciplinas e temáticas, onde as habilidades desenvolvidas, como trabalho em grupo, agilidade e capacidade de visualização de diferente perspectiva, são principalmente o que o mercado de trabalho do século XXI procura.

De acordo ainda com Larmer e Mergendoller apud Bender (2010, p. 23) "os alunos devem perceber, o projeto de ABP como sendo pessoalmente significativo para eles, a fim de alcançarem o máximo de envolvimento na resolução do problema". Os autores consideram esse fator como definidor da comparação da $\mathrm{ABP}$ e outros projetos realizados nas escolas.

Conforme pesquisas e leituras que comprovam a eficácia da $\mathrm{ABP}$, Bender (2014) confirma, que a ABP aumenta o interesse e a motivação do aluno 
em realizar o trabalho que lhe foi dado. E também que, pesquisas demonstram maior rendimento dos alunos em uma variedade de disciplinas.

\section{MATERIAIS E MÉTODOS}

A proposta de implementação do tipo de metodologia de ABP, por meio de uma atividade para o Curso Técnico em Edificações, na disciplina de Patologia das Construções/Edificações é apresentada na Figura 2. Esta disciplina tem por objetivo desenvolver as habilidades do estudante em identificar as patologias de construções e classificar as prováveis causas das mesmas. Bem como analisar as opções de soluções dos diversos tipos de patologias.

Figura 2: Infograma atividade proposta.

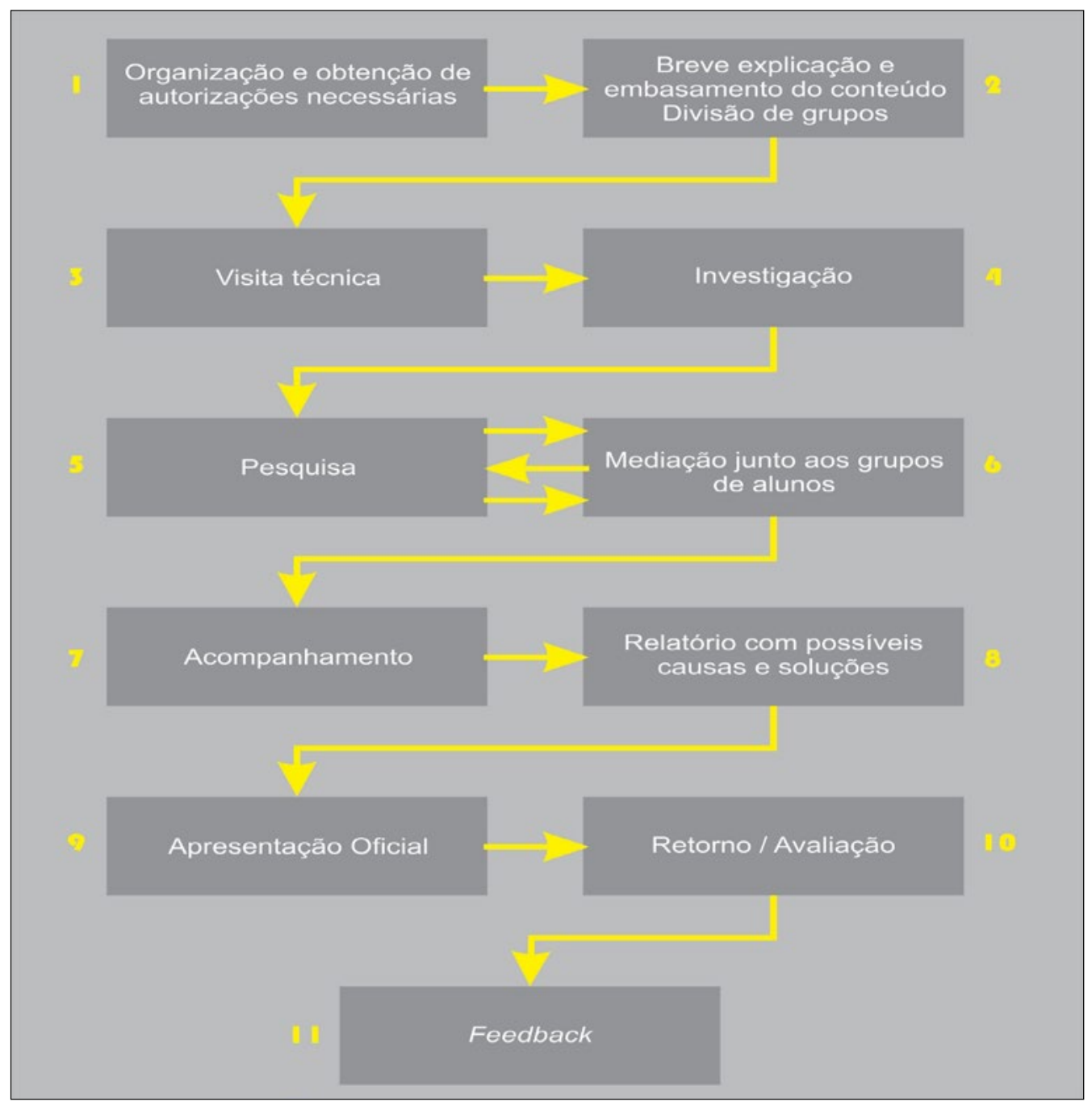

Fonte: Dos autores (2020). 


\section{Descrição das etapas apresentadas na Figura 2:}

Etapa 1: Em um primeiro momento o docente deve ir à prefeitura da cidade para solicitar sugestões de uma ou mais comunidades onde existe a possibilidade de realizar a etapa de visita. Pode também falar com os representantes das Associações de Bairros, por terem mais contato com a comunidade. Onde irá visitar juntamente com sua turma de alunos, residências em situação de problemas patológicos, de pessoas de baixa renda. Problemas estes, como infiltrações e fissuras.

Etapa 2: O docente deve então, em uma aula expositiva de curta duração, explicar sobre as patologias existentes mais comuns, de forma breve e sucinta. Explicar também aos discentes sobre a atividade. Quais informações a atividade terá que conter e, o que deve ser observado. Feito isso, o docente dividirá a turma em grupos de no máximo três integrantes. Onde cada grupo ficará responsável por ao menos uma ou duas residências, esses grupos podem ser formados a partir da afinidade entre os discentes.

Etapa 3: Com uma data marcada previamente com a prefeitura e representantes da comunidade, munidos de um documento de que ambos concordam na visita para fins acadêmicos, a turma irá acompanhada do docente até as residências selecionadas, onde devem registrar através de fotografias e anotações, todas as informações que acharem relevantes.

Etapa 4: Nesta etapa, os estudantes terão um tempo em aula para realizar de fato a atividade, onde discutirão com seu grupo sobre o que encontraram nos locais da visita. Ao final dela, é esperado que os estudantes tenham definido como realizarão a atividade. Será um momento para a organização e discussão entre eles.

Etapa 5: Nesta fase se inicia a pesquisa, onde os estudantes procurarão em livros e outras fontes por informações sobre as patologias encontradas.

Etapa 6: O professor pode sugerir bibliografias que apresentem o conteúdo, bem como auxiliar cada grupo de forma individual e, responder também questões que são de dúvida geral da turma neste momento.

Etapa 7: Durante a execução da atividade o professor faz o acompanhamento, realizando anotações sobre o que está acontecendo e o que vem percebendo. Se os alunos estão alcançando o objetivo principal.

Etapa 8: Após a conclusão das etapas anteriores, o produto da atividade é dividido em duas partes, um relatório a ser entregue ao professor na quarta aula após a visita, apresentando as patologias que encontraram, as possíveis causas destas patologias e propondo soluções para resolvê-las. Neste mesmo dia os estudantes apresentam em forma de seminário aos colegas, um arquivo de slides com as imagens das patologias encontradas e, comentam resumidamente o conteúdo do relatório que produziram. Dessa forma, pode-se gerar discussão entre os grupos, onde cada aluno pode expor sua opinião, principalmente, com os que encontraram patologias semelhantes. 
Etapa 9: Após é feito uma apresentação à comunidade, com data a ser marcada previamente, com as soluções propostas. Apresentação esta, parecida com a feita em sala de aula porém, nesta os estudantes devem levar em consideração que apresentarão para pessoas leigas no assunto, muitas vezes sem conhecimento de vocabulário técnico.

Etapa 10: A avaliação desta tarefa é realizada de forma individual, em um primeiro momento, analisando o interesse e comprometimento do aluno no desenvolvimento da atividade, e depois do resultado final é realizada a avaliação do grupo como um todo, o conteúdo do relatório, a forma de apresentação aos colegas e a forma de apresentação e, envolvimento com a comunidade. Como citam Oliveira e Araújo (2015, p. 9), "a avaliação do desempenho dos estudantes deve ser feita em relação ao processo, bem como em relação aos resultados".

Etapa 11: Ao final do processo, é proposto aos estudantes que respondam a um questionário, para que avaliem a metodologia, se gostaram deste tipo de atividade, pontos positivos e negativos, e sugestões. Esse feedback dos estudantes é importante para aprimorar e solucionar possíveis adversidades, bem como retornos que incentivem a aplicação da atividade/metodologia.

No Quadro 1 a seguir, apresenta-se o desenvolvimento da atividade conforme suas etapas e fases, com estimativa de horas. Na coluna da esquerda apresenta-se as etapas em relação ao tempo estimado de realização das mesmas, na coluna central temos as fases necessárias de cada etapa, já na coluna da direita nomeada como descrição, temos o esclarecimento de cada fase relacionada as etapas.

Quadro 1: Cronograma da atividade proposta.

\begin{tabular}{|l|l|l|}
\hline \multicolumn{2}{|l|}{ Atividade: Patologias e suas soluçães } \\
\hline Etapa/Tempo & Fase & Descrição \\
\hline $\begin{array}{l}\text { Etapa } 01 \\
\mathbf{8} \text { horas }\end{array}$ & Organização & $\begin{array}{l}\text { Docente deve ir atrás de autorizações e } \\
\text { informações necessárias a visita. }\end{array}$ \\
\hline $\begin{array}{l}\text { Etapa } 02 \\
\mathbf{2} \text { horas }\end{array}$ & Orientação & $\begin{array}{l}\text { Explicação da atividade proposta aos } \\
\text { estudantes, e breve explicação do conteúdo } \\
\text { abordado, divisão da turma em grupos. }\end{array}$ \\
\hline $\begin{array}{l}\text { Etapa } 03 \\
\mathbf{4} \text { horas }\end{array}$ & Visitação & $\begin{array}{l}\text { Visitação dos estudantes, acompanhados } \\
\text { do docente, as residências determinadas } \\
\text { anteriormente. }\end{array}$ \\
\hline $\begin{array}{l}\text { Etapa } 04 \\
\mathbf{2} \text { horas }\end{array}$ & Investigação & $\begin{array}{l}\text { Em grupos os estudantes irão discutir o que } \\
\text { encontraram. }\end{array}$ \\
\hline $\begin{array}{l}\text { Etapa } 05 \\
\mathbf{4} \text { horas }\end{array}$ & Pesquisa & $\begin{array}{l}\text { Com as patologias já identificadas os } \\
\text { estudantes realizam a pesquisa, sobre cada } \\
\text { uma delas, como surgiram, como evitá-las e } \\
\text { como solucioná-las. }\end{array}$ \\
\hline
\end{tabular}




\begin{tabular}{|l|l|l|}
\hline Atividade: Patologias e suas soluçães \\
\hline Etapa/Tempo & Fase & Descrição \\
\hline $\begin{array}{l}\text { Etapa 06 } \\
\mathbf{4} \text { horas }\end{array}$ & Mediação & $\begin{array}{l}\text { O professor faz o acompanhamento em cada } \\
\text { grupo, respondendo aos questionamentos e } \\
\text { dúvidas que possam surgir. }\end{array}$ \\
\hline $\begin{array}{l}\text { Etapa 07 } \\
\mathbf{2} \text { horas }\end{array}$ & $\begin{array}{l}\text { Faz-se um acompanhamento se os estudantes } \\
\text { conseguiram ou estão conseguindo alcançar o } \\
\text { objetivo da atividade, trabalhando em grupo. } \\
\text { E se houve a aproximação do aluno com a } \\
\text { realidade do mercado de trabalho. }\end{array}$ \\
\hline $\begin{array}{l}\text { Etapa 08 horas } \\
\mathbf{4} \text { htapa 09 }\end{array}$ & $\begin{array}{l}\text { Entrega e } \\
\text { Apresentação }\end{array}$ & $\begin{array}{l}\text { Entrega do relatório e apresentação em forma } \\
\text { de seminário com uso de slides (ou outra } \\
\text { ferramenta) aos colegas de outros grupos. }\end{array}$ \\
\hline Apresentação & $\begin{array}{l}\text { Apresentação para a comunidade com as } \\
\text { imagens das patologias e as possíveis soluções } \\
\text { aos problemas encontrados. }\end{array}$ \\
\hline $\begin{array}{l}\text { Etapa 10 } \\
-\end{array}$ & $\begin{array}{l}\text { Retorno/ } \\
\text { Avaliação }\end{array}$ & $\begin{array}{l}\text { É o momento de concluir a avaliação, de forma } \\
\text { individual e também do grupo. Analisando e } \\
\text { conferindo o grau de comprometimento e se o } \\
\text { objetivo principal foi alcançado. }\end{array}$ \\
\hline $\begin{array}{l}\text { Etapa 11 } \\
-\end{array}$ & $\begin{array}{l}\text { Reealização de um feedback, onde os estudantes } \\
\text { avaliam a atividade. }\end{array}$ \\
\hline Estimativa de horas para realização da atividade: 32 horas. \\
\hline
\end{tabular}

Fonte: Dos autores (2020).

\section{RESULTADOS E DISCUSSÃO}

Como resultados desta proposta, é esperado que os alunos atinjam o objetivo principal deste trabalho, que é a compreensão da realidade que irão encontrar quando forem para o mercado de trabalho, e que aprendam e exercitem o trabalho em grupo. Ainda, aliando a teoria e a prática, mantendo o interesse no conteúdo que lhe foi apresentado, um dos problemas encontrados pelos professores.

É esperado também, que os alunos compreendam a importância de o projeto ser bem feito, desde o seu ponto de partida até o seu detalhamento, que eles conheçam os problemas e as suas soluções. Para que dessa forma o projeto possa ser bem executado. Que se perceba também, a importância de realizar a manutenção das edificações. A fim de, evitar patologias que afetarão as pessoas que, utilizarem o espaço que eles como profissionais construíram e/ ou projetaram.

Desse modo ainda aprenderão sobre as patologias, formas de evitá-las e também como solucioná-las. E este aprendizado ocorre de forma prática, com interação direta e discussões em grupo. Também será uma forma de treinar a 
apresentação e o tato que devem ter com pessoas leigas no seu conhecimento profissional, como devem se dirigir a estas pessoas e qual vocabulário será de melhor entendimento.

Uma dificuldade que poderá ser encontrada pelo docente que deseja realizar esta atividade, é que esta proposta deve ser combinada com representantes de comunidades, bem como solicitar autorizações por escrito dos proprietários das residências, antecipadamente, para que não ocorra imprevistos ou problemas futuros.

\section{CONSIDERAÇÕES FINAIS}

A metodologia de ABP se apresenta como uma importante ferramenta para manter os alunos interessados no conteúdo, além de auxiliar na relação teoria-prática no processo de ensino-aprendizagem. Aproximando estes, do meio que encontrarão após a conclusão do curso, auxiliando no desenvolvimento dos profissionais para o mercado de trabalho, e também contribuindo na desenvoltura da relação com os colegas nos trabalhos em grupo.

Espera-se que essa atividade traga inúmeros benefícios a sociedade onde estes futuros profissionais estarão inseridos, por se tratar de uma proposta de cunho social, além de mostrar à comunidade a importância de terem suas casas construídas com profissionais qualificados e de realizarem manutenções sugeridas, a fim de, evitar problemas muitas vezes sem soluções para suas moradias e também, para sua saúde, bem-estar físico e mental.

Para que se vença todos os desafios que surgirão com a implementação de uma nova metodologia de ensino/aprendizagem, é essencial que o professor tenha uma boa organização, e que também tenha um objetivo claro, com embasamento. Os estudantes precisam ser bem orientados e incentivados, para que não desanimem com as dificuldades que irão aparecer ao longo do processo.

É esperado que a aplicação da metodologia de ensino e aprendizagem baseada em projetos se mostre satisfatória, e que possa ser percebido maior empenho e interação entre os alunos, para a resolução das problemáticas apresentadas, facilitando e contribuindo com o conhecimento adquirido. Assim, estes alunos estarão melhor capacitados para o mercado de trabalho, quando partirem em busca de sua posição e seu emprego.

\section{REFERÊNCIAS}

AGUILAR, Maria Teresa Paulino; GONÇALVES, Dayana Keitty Carmo.

Metodologias Ativas Aplicadas na Disciplina de Saneamento Ambiental no Curso Engenharia Civil: I Congresso de Inovação e Metodologias de Ensino, Belo Horizonte, 2015. 
BENDER, William N. Aprendizagem Baseada em Projetos: Educação diferenciada para o século XXI, Porto Alegre: Penso, 2014.

BERBEL, Neusi Aparecida Navas. As Metodologias Ativas e a Promoção da Autonomia de Estudantes. In Semina: Ciências Sociais e Humanas, Londrina, v. 32, n. 1, p. 25-40, jan./jun. 2011.

CIT, Luis Henrique Agulham; LIMA FILHO, Domingos Leite. A Importância da Integração Teoria-Prática no Processo de Ensino-Aprendizagem no Curso Técnico em Agropecuária: Os Desafios da Escola Pública Paranaense na Perspectiva do Professor PDE, Governo do Estado do Paraná, 2014.

DEBASTIANI, Rafael Tiago; Alternativas de Avaliação em Metodologias Ativas no Ensino Fundamental. In: Metodologias Ativas: Desafios para uma Educação Disruptiva. 1. ed. Porto Alegre: Propale.com, 2016.

DIESEL, Aline; MARCHESAN, Michele Roos; MARTINS, Silvana Neumann. Metodologias Ativas de Ensino na Sala de Aula: Um Olhar de Docentes da Educação Profissional Técnica de Nível Médio. In Revista Signos, Lajeado, ano 37, n. 1, p. 153-169, 2016.

LARIOS, Mario Roberto Barraza; PASETO, Rosana Celia. Ensino por Projetos: A Engenharia Civil Empregando as Metodologias Ativas de Ensino-Aprendizagem: Congresso Técnico Científico da Engenharia e da Agronomia, Foz do Iguaçu, 2016.

LORENZONI, Marcela. Aprendizagem Baseada em Projetos (PBL) em 7 passos I Infográfico. Disponível em: < http:/ / info.geekie.com.br/aprendizagem-baseada-emprojetos>. Acesso em: 05 de março de 2019.

OLIVEIRA, Agostinho Carlos; ARAÚJO, Samira Maria. Métodos Ativos de Aprendizagem: uma breve introdução. Disponível em: <https:/ / www.researchgate. net/publication/280091153>. Acesso em: 13 de fevereiro 2019.

RECHLINSKI, Milene Duarte; SCHWERTNER, Suzana Feldens. Andragogia na Educação Profissional. Disponível em: <https:/ / www.univates.br/bdu/ bitstream/10737/2020/1/2017MileneRechlinski.pdf>. Acesso em: 13 de julho de 2020. 